\title{
Reforming and Strengthening the Centers for Disease Control and Prevention: Five Key Reforms to Renew the Agency's Stature and Effectiveness
}

\author{
Lawrence 0. Gostin \\ Georgetown University - Law Center - O'Neill Institute for National and Global Health Law, \\ gostin@law.georgetown.edu \\ Sandro Galea \\ Boston University School of Public Health
}

This paper can be downloaded free of charge from:

https://scholarship.law.georgetown.edu/facpub/2336

https://ssrn.com/abstract=3747082

Reforming and Strengthening the Centers for Disease Control and Prevention: Five Key Reforms to Renew the Agency's Stature and Effectiveness. Milbank Quarterly Opinion. November 30, 2020.

This open-access article is brought to you by the Georgetown Law Library. Posted with permission of the author. Follow this and additional works at: https://scholarship.law.georgetown.edu/facpub

Part of the Administrative Law Commons, Health Law and Policy Commons, International Humanitarian Law Commons, and the Law and Politics Commons 


\title{
Reforming and Strengthening the Centers for Disease Control and Prevention Five Key Reforms to Renew the Agency's Stature and Effectiveness
}

\author{
Lawrence O. Gostin and Sandro Galea
}

The US Centers for Disease Control and Prevention (CDC) is the world's leading public health agency, so admired that whole regions and countries have borrowed its name-in Africa, Europe, even China. In past epidemics, CDC's expertise was transformative, such as in AIDS, Ebola, Zika, and Influenza H1N1. If there ever were a moment for the CDC to show leadership domestically and globally, it was the COVID19 pandemic. Yet, the CDC's stature was diminished-not enhanced-in an administration that not only eschewed science and politically pressured the $C D C$, but also gave notice of withdrawal from the World Health Organization (WHO), where CDC staff were firmly embedded. Recognizing where the CDC fell short in 2020 can inform the Biden Administration how to reform and strengthen the nation's public health agency. Deep structural reform should occur in at least five critical areas.

First, a renewed CDC must be fiercely independent, guarding against political interference and empowered to develop scientific evidence rigorously and to issue public health guidance authoritatively. This requires a leader who has the stature to do that, but perhaps more importantly, a leader who is encouraged to stick to the values of science that are crucial to agency credibility and effectiveness. CDC leadership must put health at the center of the national conversation and to lead public health action nationwide, in close partnership with state, tribal, and local health departments.

Putting science before politics is the highest priority for reform. In the past few years, the CDC's leadership has been visibly and repeatedly undermined, both in private and in public. Even before COVID-19, the White House advised the CDC not to use terms like "science-based" or "evidence-based" in its budget requests. Unlike previous outbreaks, the agency rarely made its case directly to the public. Nor did it become the voice of public health during the COVID-19 pandemic. The Trump White House exercised intrusive oversight of the CDC's words and actions. It required political clearance or even blocked key CDC guidance. The White House dictated when, and even what, the CDC director and his deputies could say. The agency also was required to obtain political clearance to change health education messages on its website. This is what happens when a scientific agency is captured for political purposes: the CDC's authority, legitimacy, and effectiveness were all hobbled when the nation needed it the most.

Second, a renewed CDC must have impeccable scientific expertise and must demonstrate efficient execution of public health policies. During COVID-19, public confidence in the CDC eroded sharply on the heels of high-profile technical missteps. Centrally, the CDC failed to develop a high-quality COVID-19 test early in the pandemic's first wave. Instead of purchasing proven tests from the WHO or allies like Germany, the CDC delivered a flawed test to health departments, while insisting that CDC labs conduct test analyses, engendering long delays in test results. The testing fiasco earned the CDC public criticism, rendering the agency vulnerable to critics and agendas designed to gain political advantage.

It is next to impossible to prescribe a fix to technical problems from the outside. These crucial errors can be avoided in the future only through a comprehensive review of the CDC's staffing and operations that considers carefully how the CDC performs in the face of a health emergency. An internal review should 
also partner with independent scientists and civil society partners to enhance insight and accountability. Agency leadership must ensure that the CDC has the flexibility and expertise to rise to future challenges.

Third, a renewed CDC must have a health information infrastructure that earns public trust. Its public health messaging must be clear, consistent, and trustworthy. The CDC's communications during the pandemic proved inconsistent, even in areas where it was apparently not under political duress. The public was distrustful of CDC communications that appeared to be changing, without clear rationales, throughout the pandemic. In particular, its guidance shifted on core epidemiologic issues, including masks, asymptomatic transmission, and aerosolized transmission of SARS-CoV-2. It is always hard to deliver health guidance with science rapidly evolving, as it does early in novel disease outbreaks. Yet, the CDC should be able to deliver messages that are clear on what it knows, what it does not know, and what the agency is doing to fill the knowledge gaps. A reliable and effective communication strategy ought to be part of the comprehensive review we urge.

Fourth, a renewed CDC requires a commitment to its workforce, an investment in its existing scientific staff, ensuring that they are recognized for their service to the nation throughout repeated health threats faced domestically and globally. The CDC is staffed by the world's most respected public health professionals. Yet, the CDC's workforce is demoralized, feeling under siege and under-appreciated despite the overwhelming intensity of their responsibilities. CDC employees should be closely engaged in an urgent refresh of the agency under new leadership. The CDC cannot, and does not need to, engage in wholesale turnover of staff. But it does need to realign how it operates and how it can operate within a politicized environment. That is achievable, and the CDC staff need to be part of finding solutions for a stronger CDC in the long term.

Finally, none of this is achievable without sustained investment commensurate with the CDC's national and global mandate. Funding must be sufficiently predictable and robust to enable the CDC to extend its reach and meet the challenges posed by the moment. The CDC has faced a series of funding cuts, with repeated political threats of further budget cuts. There have been episodic investments in the agency, such as during the West African Ebola epidemic and more recently in the coronavirus stimulus bill. But episodic funding surges do not bolster CDC data systems and infrastructure. A pattern of repeat injections of emergency funds does not allow the CDC to renew its core functions-a pattern that was directly responsible for an underfunded agency facing the worst pandemic in a century.

We fully recognize it is easy, far too easy, to point fingers at an agency that has been under indescribable strain during COVID-19. There is a fundamental unfairness in many of the criticisms levied against the CDC during the pandemic. Our reform proposals are predicated on a bedrock of respect for what the CDC has been, is, and will be. Our goal is to empower the agency and to regain the public and political trust it richly deserves.

The Biden presidency presents an opportunity for a renewed focus on reforming and strengthening the CDC. We suggest that five top priorities-strengthening leadership and its independence from political interference, reviewing and shoring up operational capacity, improving health communications, renewing and reinvigorating the workforce, and sustainable funding - can go a long way to returning the CDC to its place as the world's pre-eminent public health agency. This will require public support and political commitment, but is eminently doable. We urge President Biden and a new CDC director to begin this renewal process as one of the nation's highest priorities. 